\title{
Abordagem investigativa no ensino da gravitação a partir de buracos negros
}

\author{
Scherrer Neto, J. I. M. ${ }^{* 1}$, Alvarenga, F. G ${ }^{2}$, Coelho, G. R ${ }^{3}$ \\ 'Universidade Federal do Espírito Santo, PPGEnFis/MNPEF Polo 12, ES, Brasil \\ ${ }^{2}$ Universidade Federal do Espírito Santo/Departamento de Física/PPGEnFis/MNPEF Polo 12, ES, Brasil \\ ${ }^{3}$ Universidade Federal do Espírito Santo/Departamento de Teorias do Ensino e Práticas \\ Educacionais/PPGEnFis/MNPEF Polo 12, ES, Brasil
}

*netoscherrer@hotmail.com

\begin{abstract}
Resumo
Com a crescente necessidade de introdução da Física Moderna e Contemporânea e a busca de melhoria das aulas de Física no ensino básico, propõe-se nesse trabalho a construção de uma sequência didática, que permita o ensino da Gravidade através de atividades com foco nos buracos negros. As atividades foram planejadas e fundamentadas no ensino por investigação, o qual permite uma maior liberdade intelectual do aluno, estando ele no centro de todo o processo de aprendizagem. O tema integrador e motivador escolhido foi o buraco negro, objetos cosmológicos que estão no imaginário da população e que despertam a curiosidade desta. Devido a todos os transtornos gerados pela pandemia da covid-19, a sequência passou por um processo de validação a priori, onde alunos e professores por intermédio de um instrumento de avaliação, validação e análise de sequências de ensino investigativo, avaliaram e analisaram a sequência de ensino. Para nossa análise de dados, iremos neste momento considerar somente as respostas obtidas pelo instrumento respondido pelos alunos.
\end{abstract}

\begin{abstract}
With the growing need for the introduction of modern and contemporary Physics and the search for improving Physics classes in basic education, we seek in this work the construction of a didactic sequence, which allows the teaching of Gravity through activities focusing on black holes. The activities were planned and based on teaching by research, which allows greater intellectual freedom for the student, being at the center of the entire learning process. The integrating and motivating theme chosen was the black hole, cosmological objects that are in the imagination of the population and that arouses interest. Due to all the disorders generated by the covid-19 pandemic, the sequence underwent a priori validation process, where students and teachers, through an instrument of evaluation, validation and analysis of investigative teaching sequences, evaluated and analyzed the sequence education. For our data analysis, we will now consider only the answers obtained by the instrument answered by the students.
\end{abstract}

Palavras chaves: Ensino por investigação, Validação a priori, Aprendizagem, Buraco negro.

\section{Introdução}

Existe inúmeros desafios para melhoria do ensino de Física no nível básico, fazendo com que pesquisadores/professores repensem as práticas e conceitos desenvolvidos em sala de aula. Um tópico que tem sido cada vez mais discutido, é a introdução da Física Moderna e Contemporânea nas aulas.

Segundo DOMINGUINI, MAXIMIANO e CARDOSO (2012), o conteúdo que o professor trabalha nas aulas de Física é desatualizado e não acompanha o crescente desenvolvimento da ciência nas últimas décadas.
Essa desatualização fortalece o cenário em que os alunos acham que a Física se resume em leis e fórmulas acabadas, fortalecendo um ensino memorista, incompatibilizando a utilidade e a aplicabilidade desses conceitos relevantes para uma sociedade contemporânea na vida dos alunos (Silva Júnior e Coelho, 2020).

O cenário poderá mudar, se houver um comprometimento em trazer uma Física mais atualizada e próxima dos alunos, de maneira que se sintam desafiados e percebam que ainda há muito o que descobrir, transmitindo uma imagem mais correta dessa ciência e do próprio trabalho científico. 
Para TERRAZZAN 1992, uma das possíveis maneiras de trabalhar a Física Clássica articulada com a Física Moderna e Contemporânea, de forma que tenha aceitação e não contraponha os conteúdos prédeterminados pelo currículo escolar, consiste na exploração dos limites dos modelos físicos. Mostra-se historicamente o desenvolvimento dos conceitos e reforça-se a ideia de que na Física, certos modelos funcionam bem em determinadas situações, mas pode ser necessário o desenvolvimento de novas teorias para o entendimento de situações diversas.

Juntamente com o esforço da introdução da Física Moderna e Contemporânea, é extremamente necessário que os planejamentos das atividades sejam embasados em uma abordagem que permite a centralidade nos alunos, liberdade intelectual, desenvolva a habilidade na resolução de problemas, crie um ambiente democrático, e facilite a alfabetização cientifica nas escolas. Segundo da Silva Junior e Coelho (2020), o ensino por investigação é uma excelente estratégica para que se alcance melhorias no ensino de Física, possibilitando o desenvolvimento dos critérios pertinentes para uma educação de melhor qualidade.

O ensino por investigação contrapõe o modelo tradicional e contribui para um ensino consciente, facilitando o aprendizado na área da ciência bem como o desenvolvimento de suas habilidades e competências, formando cidadãos idôneos em seu papel na sociedade (SILVA, 2014).

Trabalhar atividades na perspectiva investigativa não necessariamente significa ter uma metodologia de indicando uma estrutura fechada e bem definida. As atividades investigativas possibilitam uma diversificação de formas a se trabalhar os conteúdos em sala de aula (DA SILVA JUNIOR e COELHO, 2020).

Para que a aula aconteça nessa perspectiva, tanto o professor quanto o aluno devem exercer os papéis a eles designados. O aluno como um verdadeiro investigador e o professor como mediador do processo (DA SILVA JUNIOR e COELHO, 2020). Por se constituir um ambiente dinâmico, prezando a interação entre os envolvidos, a reflexão e analise da aula para a caracterizar como investigativa, só ocorrerá na análise detalhada dessas interações e do processo como todo. Mas instrumentos devem ser utilizados para que 0 material seja anteriormente analisado, para que haja uma ressignificação e melhoria das atividades, tornando-o potencialmente apto a atingir o objetivo educacional.

\section{Metodologia}

Este trabalho refere-se a uma pesquisa quantitativa, onde buscamos através do instrumento de avaliação, validação e análise de sequências de ensino investigativo, a validação da SEI. Essa pesquisa foi realizada com treze alunos do ensino médio, sendo dois da primeira série, seis da segunda série e cinco da segunda série, todos da Escola Estadual de ensino Médio Leandro Escobar.

A coleta de dados foi realizada através do instrumento de avaliação, validação e análise de sequências de ensino por investigação disponibilizado em forma de formulário. Buscou-se analisar e avaliar três parâmetros: o tema a ser abordado nas aulas, se o mesmo possui originalidade e desperta o interesse; clareza e compreensão, se as atividades possuem uma redação clara e direta, contendo todas as explicações necessárias para seu desenvolvimento; e o método de avaliação, se é condizente com os objetivos e conteúdos propostos, e informado com clareza antes do início das atividades.

Junto com o instrumento, foi encaminhado as atividades que compõem a SEI, para que os alunos analisassem e avaliassem. A sequência é composta pelas seguintes atividades:

\begin{tabular}{|c|}
\hline Atividades \\
\hline Atividade investigativa do modelo planetário \\
\hline Atividade investigativa das órbitas dos satélites \\
\hline Atividade investigativa da velocidade de escape \\
\hline Demonstração investigativa da cama elástica \\
\hline Atividade investigativa sobre os buracos negros \\
\hline Atividade investigativa do raio de Schwarzschild \\
\hline Atividade investigativa sobre a "Espaguetificação da \\
astronauta" \\
\hline
\end{tabular}

\section{Discussão dos resultados}

Apresenta-se agora a seguinte análise dos dados coletados através das respostas enviadas pelos alunos. Em relação ao tema:

O tema desenvolvido na sequência desperta o interesse em participar das aulas?

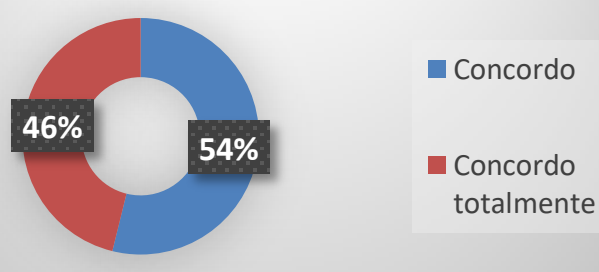


Fica bem claro que o tema é, segundo os alunos um atrativo a participar das aulas propostas nessa sequência. Segundo Ostermann e Moreira (2000), a utilização de conceitos da Física Moderna pode desperta o interesse dos alunos pela ciência, fazendo com que tenham vontade de participar do processo de aprendizagem.

Em relação a clareza e compreensão:

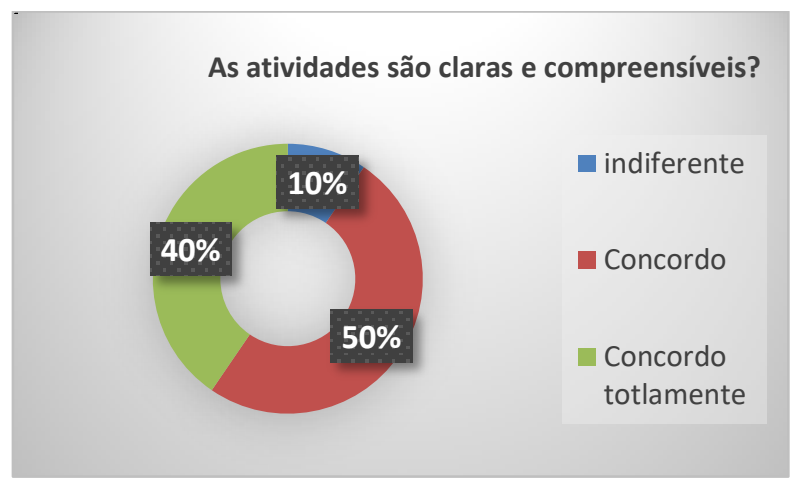

Para a maioria, as atividades apresentadas são claras e compreensivas, tendo um texto bem redigido e de fácil entendimento, porém dez por cento ficaram indiferente a essa questão.

Em relação ao método de avaliação:

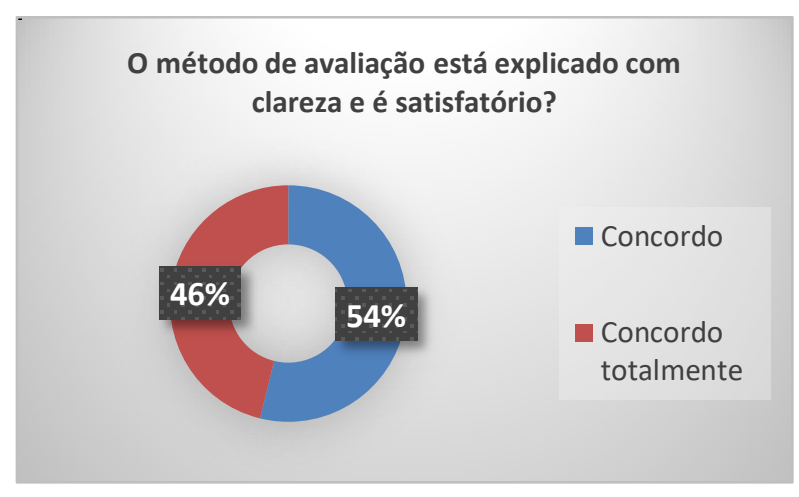

Todos concordam ou concordam totalmente que o método de avaliação é satisfatório e atende a excepcionalidade das atividades propostas.

\section{Conclusão}

Conclui-se então que as atividades da sequência investigativa constituem um material com potencial para atingir o objetivo educacional, desde que a mediação e as interações atendam o referencial proposto.

A sequência desse trabalho consistirá na análise dos dados coletados pela aplicação do instrumento de avaliação para professores.

\section{Agradecimentos}

Os autores agradecem à FAPES pelo apoio financeiro.

\section{Referências}

MAXIMIANO, J. R. ; CARDOSO, L. ; DOMINGUINI, L. . Física Moderna nos livros didáticos: um contraponto entre o PNLEM 2009 eo PNLD 2012. Vidya (Santa Maria. Impresso), v. 33, p. 97-115, 2013.

SILVA JÚNIOR, JOÃO MAURO DA; COELHO, GEIDE ROSA . O ensino por investigação como abordagem para o estudo do efeito fotoelétrico com estudantes do ensino médio de um Instituto Federal de Educação, Ciência e Tecnologia. CADERNO BRASILEIRO DE ENSINO DE FÍSICA, v. 37, p. 51-78, 2020.

TERRAZZAN, E. A.. A inserção da física moderna e contemporânea no ensino de física na escola de segundo grau. Caderno Catarinense de Ensino de Física, Florianópolis, SC, Brasil, v. 9, n.3, p. 209-214, 1992.

SILVA, V. M. O ensino por investigação e o seu impacto na aprendizagem de alunos do ensino médio de uma escola pública brasileira. Dissertação. Programa de Pós-Graduação em Educação em Ciências: Química da Vida e Saúde. Universidade Federal do Rio Grande do Sul. Porto Alegre, 2014.

OSTERMANN, Fernanda; MOREIRA, M. A. . Uma revisão bibliográfica sobre a área de pesquisa Física Moderna e Contemporânea no Ensino Médio. Investigações em Ensino de Ciências (Online), Porto Alegre, v. 5, n.1, p. 23-48, 2000. 


\section{Anexo}

\begin{tabular}{|l|l|l|l|l|l|}
\hline \multicolumn{1}{|c|}{ INSTRUMENTO DE ANÁLISE, AVALIAÇÃO E VALIDAÇÃO DAS SEQUÊNCIAS DE ENSINO } \\
INVESTIGATIVO
\end{tabular}

